\title{
THE EFFECT OF BINDERS ON THE BIO- AVAILABILITY OF OFLOXACIN TABLETS IN HUMAN VOLUNTEERS
}

Naveed Akhtar ${ }^{1}$, Muhammad Shoaib Khan ${ }^{1}$, Mahmood Ahmad ${ }^{1}$, Gulzeb Aziz ${ }^{1}$ and Mohammad Aleem ${ }^{2}$

${ }^{1}$ Department of Pharmacy, Faculty of Pharmacy and Alternative Medicine, The Islamia University of Bahawalpur, Pakistan

${ }^{2}$ Department of Statistics, Faculty of Science, The Islamia University of Bahawalpur, Pakistan

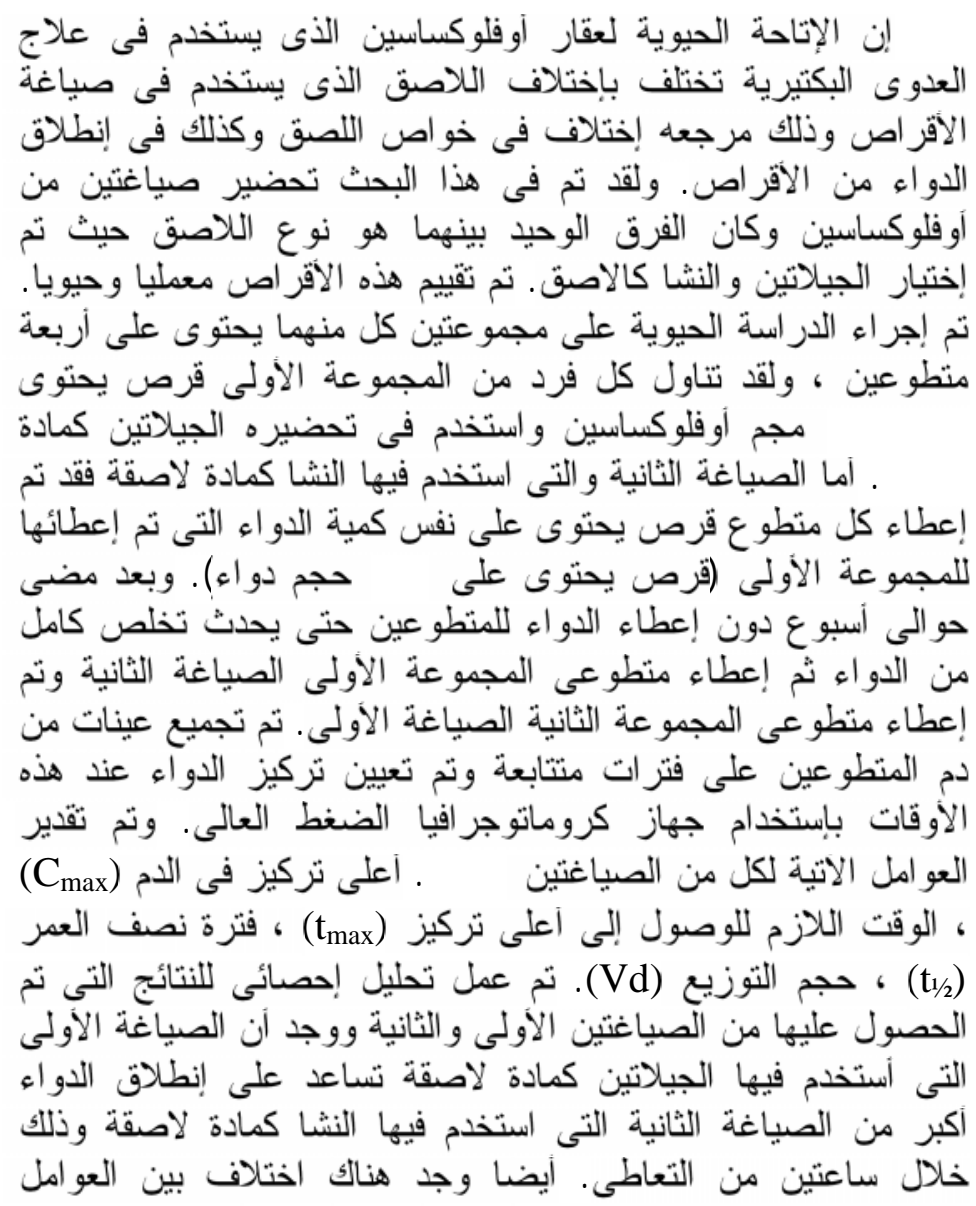

Received in 22/11/2005 \& Accepted in 8/6/2006 


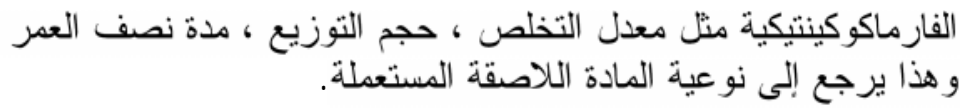

The bioavailability of ofloxacin, a fluoroquinolone widely used in the treatment of bacterial infection varies different with different binders used in the formulation of tablets due to different binding properties and variable release characteristics.

In this study, two formulations of ofloxacin were prepared. The only difference between them was of binder. The two binders used were gelatin and starch. In-vitro and in-vivo evaluation of tablets was performed. Eight healthy human volunteers were selected for this study, and were divided into two groups each consisting of 4 volunteers. First group was given formulation 1 with gelatin as binder. Each volunteer received $200 \mathrm{mg}$ ofloxacin tablet. Volunteers of the second group were given formulation 2 with starch as binder. After one week wash out period, volunteers of the first group received formulation 2 and volunteers of second group received formulation 1. Blood samples were collected at different time intervals. The drug concentrations in plasma were assayed by High Performance Liquid Chromatography.

Pharmacokinetic parameters of formulation 1 were $C_{\max } 1.4412$ $\pm 1.8367 \mu \mathrm{g} / \mathrm{ml}, t_{\max }$ was $1.00 \pm 0.00$ hours, AUC $8.6804 \pm 0.8346$ $\mu \mathrm{g} . \mathrm{h} / \mathrm{ml}, \mathrm{AUMC} 43.017 \pm 0.2893 \mu \mathrm{g} . \mathrm{h}^{2} / \mathrm{ml}, \mathrm{MRT} 4.8869 \pm 1.3587$ hours, Ke $0.2067 \pm 6.9207, T^{1 / 2} 3.3886 \pm 1.6321$ hours, Vd $113.826 \pm 0.2983 \mathrm{~L} / \mathrm{Kg}$, Vss $4.833 \pm 0.9138 \mathrm{~L} / \mathrm{Kg}, \mathrm{Cl} 23.595 \pm$ $0.5070 \mathrm{ml} / \mathrm{h} / \mathrm{Kg}$. For Formulation 2 these values were $1.515 \pm$ $1.5898 \mu \mathrm{g} / \mathrm{ml}, 0.5 \pm 0.00$ hours, $9.0317 \pm 0.8805 \mu \mathrm{g} . \mathrm{h} / \mathrm{ml}$, $35.4486 \pm 0.3337 \mu \mathrm{g} . \mathrm{h}^{2} / \mathrm{ml}, 3.8798 \pm 1.4668$ hours, $0.2606 \pm 6.0291$, $2.68 \pm 1.76$ hours, $86.609 \pm 0.3354 \mathrm{~L} / \mathrm{Kg}, 5.94 \pm 0.84 \mathrm{~L} / \mathrm{Kg}, 22.580$ $\pm 0.5333 \mathrm{ml} / \mathrm{h} / \mathrm{Kg}$ respectively.

Statistical analysis was performed and it was found that the formulation 1 (formulated with gelatin) released the drug slightly greater than the formulation 2 within two hours after its administration. There was highly significant difference between mean residence time, elimination rate constant, half life and volume of distribution between both of the formulations. Therefore, formulation 2 has greater bioavailability than the formulation 1 . Thus it can be concluded that the binder can affect the bioavailability and pharmacokinetic parameters of a drug. 


\section{INTRODUCTION}

\section{Effects of ofloxacin}

Ofloxacin is a new fluoroquinolone with a spectrum of activity similar to other fluoroquionolones with activity which includes Chlamydia trachomatis, Mycobacterium spp., Mycoplasma spp. and Legionella pneumophila. Through its additional mechanisms of action, ofloxacin may be less susceptible to the development of resistance from Staphylococcus aureus commonly seen with currently available flouroquinolones. The impact of these findings cannot be evaluated without further clinical experience. The pharmacokinetics of ofloxacin are characterized by almost complete bioavailability (95 to $100 \%$ ), peak serum concentrations in the range of 2 to $3 \mathrm{mg} / \mathrm{L}$ after a $400 \mathrm{mg}$ oral dose and an average half life of 5 to $8 \mathrm{~h}$. In comparison with other available quinolones, elimination is more highly dependent on renal clearance, which may lead to more frequent dosage adjustments in patients with impaired renal function.

\section{Pharmacokinatics}

Ofloxacin appears less likely to affect the pharmacokinetics of drugs (e.g. theophylline) which commonly interact with fluoroquinolones such as ciprofloxacin and enoxacin. The properties of ofloxacin make it a therapeutic alternative to currently available flouroquinolones.

Clinical usefulness of nalidicix acid is limited by the rapid emergence of resistant strain. Most of the absorbed drug i.e., $90 \%$ is protein bound and levels of the free drug are therefore inadequate for the treatment of systemic infection. ${ }^{1}$ Fluoroquinolones are highly effective against gram positive and gram negative bacteria both in vino and invitro with few of the problems of their predecessors. ${ }^{2}$ The spectra of activity of the fluoroquinolones against these organisms appear comparable; however, differences emerge against other microorganisms, such as Chlamydia trachomatis, Mycobacterium spp. and Mycoplasma pneumoniae

Ofloxacin is a broad spectrum antibiotic with poor activity against anaerobes. ${ }^{3-8}$ The ofloxacin minimum inhibitory concentration (MIC) for $90 \%\left(\mathrm{MIC}_{90}\right)$ of Enterobacteriaceae isolates (range 0.6 to $4 \mathrm{mg} / \mathrm{L}$ ) would indicate inferior activity compared with ciprofloxacin. ${ }^{9}$ This may not be clinically significant since ofloxacin achieves higher serum concentrations. Gram- positive bacteria are similarly sensitive to ofloxacin and ciprofloxacin, with Staphylococci spp. more sensitve than Streptococci spp. As with other available fluoroquinolones, Streptoccoci are only moderately sensitive to ofloxacin with MIC values ranging from 1 to 4 mg/L. ${ }^{10}$ Pseudomonas spp. exhibit differing susceptibilities. Pseudomonas aeruginosa and nonaeruginosa species are less susceptible to ofloxacin than to ciprofloxacin, however, ofloxacin is at least as active against Xanthomonas maltophilia. ${ }^{3}$ Ofloxacin 
is active against Clostridium perfringens but few other anaerobes are inhibited at obtainable serum concentrations. Legionella pneumophila and Mycobacterium tuberculosis are also susceptible to ofloxacin. $C$. trachomatis is very sensitive to ofloxacin with Ureaplasma urealyticum and Mycoplasma hominis only moderately susceptible. In situations of comparable serum concentration to MIC ratios and efficacy, the choice of quinolone may be more influenced by dosag intervals and drug interactions than minor differences in in-vitro activity.

\section{The aim of the work}

Excepients are added to the formulations to produce certain properties to the drug and dosage form. Some of these properties of the excepients are used to improve the compatibility of the active drug. Stabilize the drug against, degradation, gastric irritation; control the rate of drug absorption increase drug bioavailability etc. Excepients in a drug product may also affect the dissolution kinetics of the drug. Excepients may be added intentionally to the formulation to enhance the rate and extent of drug absorption or to delay or slow the rate of drug absorption. Excepients in formulation may interact directly with the drug to form a water soluble or water insoluble complex, e.g., if tetracycline is formulated with calcium carbonate, an insoluble complex of calcium tetracycline is formed that has a slow rate of dissolution and poor absorption. Several studies show that changing the excepients in a formulation changes the bioavailability and pharmacokinetics of the active drug.

Binding material can also affect the release of active drug material from formulation which also affects bioavailability of active drug. So different binders affect the pharmacokinetics of drug.

\section{MATERIALS AND METHODS}

\section{Chemicals}

Ofloxacin (Aventis Pharma Karachi), Gelatin (Merck, Germany),Lactose (Riedel, Holland), Carboxymethyl cellulose (BDH, Germany), Starch (Merck, Germany), Magnesium Stearate (Merck, Germany), Talc (Merck, Germany), Cellulose Acetate Phthalate (Fluka, Switzerland), Propylene Glycol (Merck, Germany), Methylene Chloride (BDH, England), Alcohol (Merck, Germany), Hydroxypropyl Methyl Cellulose (BDH, England), Propylene Glycol, USP (Merck, Germany), Ethyl Alcohol, 200 proof (Merck, Germany), Acetonitrile (Merck, Germany), Disodium Hydrogen Phosphate (Sigma, Germany), Triethylamine (Merck, Germany), Double Distilled Water (Islamia University Bahawalpur).

\section{Methods}

Preparation of tablets

$\begin{array}{ll}\text { Ofloxacin } & 60 \mathrm{~g} \\ \text { starch } & 19.5 \mathrm{~g} \\ \text { Lactose } & 36.15 \mathrm{~g}\end{array}$


Gelatin for paste

$8.1 \mathrm{~g}$

Magnesium Stearate

Carboxy methyl cellulose $13.5 \mathrm{~g}$

Talc

Corn starch

$1.5 \mathrm{~g}$

$9 \mathrm{~g}$

Two batches of Ofloxacin $200 \mathrm{mg}$ tablets (400 tablets each) were prepared by using two different binders i.e. gelatin and starch by wet granulation method with single punch machine (Local made).

\section{Determination of drug content}

Tablets of each formulation were triturated in a mortar to fine powder form. $100 \mathrm{mg}$ of the powder was then dissolved in $100 \mathrm{ml} 0.1 \mathrm{~N} \mathrm{HCl}$. The solution in the flask was filtered and $1 \mathrm{ml}$ of this solution pipetted out in $100 \mathrm{ml}$ volumetric flask. Volume was made upto $100 \mathrm{ml}$ with $0.1 \mathrm{~N} \mathrm{HCl}$ and the contents of Ofloxacin were determined using spectrophotometer at a wavelength of $294 \mathrm{~nm}$. The analysis was conducted in sets of six and the average was then calculated.

\section{In-vitro disintegration studies}

The in-vitro disintegration time of both formulations was determined using USP disintegration apparatus six vessel appartus (local made) using water as disintegration medium. Temperature was adjusted $37 \pm 2^{\circ}$. The disintegration time of two formulations was compared.

\section{In-vitro dissolution studies}

The in-vitro ofloxacin release was determined using USP 2 dissolution apparatus (Curio, Pakistan) for both formulations using $0.1 \mathrm{~N} \mathrm{HCI}(900$ $\mathrm{ml}$ ) as dissolution medium and at temperature $37 \pm 0.2^{\circ}$ and paddle speed was set at $100 \mathrm{rpm}$.

\section{In-vivo study protocol}

In-vivo study was conducted according to the randomized two way crossover design. Eight healthy, non smoking adult male volunteers with ages between 22 and 24 years old (mean $=22.62$ years) their heights range from $154 \mathrm{~cm}$ to $169 \mathrm{~cm}$ (mean $=159.5 \mathrm{~cm}$ ), and weighing from 56 $\mathrm{kg}$ to $61 \mathrm{~kg}($ mean $=59.5 \mathrm{~kg})$ participated in the study. The volunteers were divided into two groups, four volunteers in each group. Written informed consent was obtained from each volunteer after explaining the nature and the purpose of the study. All were found healthy after performing their complete blood and urine analysis and were not receiving any medication prior two weeks and during the study period.

All the four volunteers of group 1 each was administered one tablet (200 $\mathrm{mg}$ ) of formulation 1 in random and all the volunteers of group 2 were administered one tablet of formulation two individually. After a washout period of one week, each volunteer of group 1 was given one tablet $(200 \mathrm{mg})$ of formulation 2 and each volunteer of group 2 was given one tablet of formulation one. Both the formulations were administered with $240 \mathrm{ml}$ of water after an overnight fasting. After 2 hours of dosing each subject was provided with breakfast consisted of 2 
scrambled eggs, four pieces of toast and one glass of milk. Blood samples of $5 \mathrm{ml}$ volume were collected in preheparinized syringes at 0 (before dosing), 0.5, 1.0, 2.0, 4.0, 6.0, 8.0, $10.0,12.0$ and 24.0 hours after dosing via an in-dwelling cannula placed in the forearm. The plasma was harvested and frozen at $-15^{\circ}$ until assayed.

\section{Assessment of ofloxacin concentra- tion in plasma}

The plasma samples were analysed using reversed phase high performance liquid chromatography (HPLC) method. A Hypersil ODS reversed phase column $(5 \mu \mathrm{m}, 250$ $\mathrm{mm} \times 4.6 \mathrm{~mm} \mathrm{ID)}$ was used for the separation. The detector was operated at $294 \mathrm{~nm}$. The mobile phase consisted of distilled water, Acetonitrile and triethylamine (700:300:1.4). Adjusted the $\mathrm{pH}$ at 2.4 with orthophosphoric acid. Filtered the mobile phase by passing through filtration assembly under vacuum pressure of 150-200 torr using 0.45 $\mu \mathrm{m}$ membrane filter (sartorius). Now degassed the mobile phase by flushing it with nitrogen for 2-3 min. until complete degassing of the mobile phase was ensured. Analysis was run at a flow rate of $1.0 \mathrm{ml} / \mathrm{min}$ and quantified with peak height.

Prior to injection, ofloxacin was extracted from the plasma samples according to the following procedure: Extraction procedure was simply based on liquid-liquid extraction method. ${ }^{11}$ In the extraction procedure $0.5 \mathrm{ml}$ of the drug solution was spiked with $0.5 \mathrm{ml}$ of the blank plasma in the $2 \mathrm{ml}$ of the centrifuge tube and mixed well, then centrifuged for $10 \mathrm{~min}$. Separated the organic layer by micropipette, filtered by using of the filtration syringe. And the filtrate was taken in polypropylene tubes. $20 \mu \mathrm{l}$ was injected in to the HPLC injection port by injection syringe. Standard curve was prepared to encompass the anticipated range of plasma ofloxacin concentration found in healthy subjects taking ofloxacin. Blank plasma was spiked with ofloxacin drug solution to give the concentrations of $0.5,1.0,2.0,4.0$, $8.0 \mu \mathrm{g} / \mathrm{ml}$. The extraction procedure was same as described earlier. Injections of $20 \mu 1$ were injected and spectra were taken of each concentration. The peak areas were noted for each concentration. The absolute recovery of ofloxacin from the extraction procedure was determined at different plasma concentrations ( 0.5 to $8 \mu \mathrm{g} / \mathrm{ml}$ ) by comparing the peak heights of the drug obtained from extracted plasma samples with those obtained from direct injections of the pure ofloxacin standards in water of equivalent amounts.

\section{Data analysis}

Pharmacokinetic analysis was performed by using MS Excel Windows Professional XP. PK analysis was performed by using noncompartmental model. Maximum concentration of Ofloxacin in serum $\left(\mathrm{C}_{\max }\right)$ and times to these concentrations $\quad\left(\mathrm{T}_{\max }\right) \quad$ were 
determined by visual inspection of plasma concentration time profiles. At each time points $(\mathrm{t}),\left(\mathrm{Ct} / \mathrm{C}_{\max }\right) \mathrm{X}$ $100 \%$ / individual was calculated, and the maximum, median and minimum values across all subjects were determined. These $\%$ ages can provide some guidance regarding sampling times that can be used clinically. The area under the concentration time curve from 0 hour - infinity $\left(\mathrm{AUC}_{0-\infty}\right)$ was calculated by the linear trapezoidal rule using the AUC from 0 hour to last measure concentration $\left(\mathrm{C}\right.$ last) plus $\mathrm{C}$ last $/ \mathrm{K}_{\mathrm{el}}$ where $\mathrm{t}$ last is the time of the last measured concentration and $\mathrm{Ke}$ is the terminal elimination rate constant.

\section{Statistical analysis}

Statistical analysis was performed by using SPSS 7. Paired t-test was used to check the differences between the parameters of two formulations. For this purpose average concentration of the two formulations were taken and analyzed by the SPSS 7.

\section{RESULTS AND DISCUSSION}

\section{In-vitro evaluation}

Percentages of active ingredients of both the formulations were noted and have been presented in the Table 1. Both formulations of ofloxacin tablets were analyzed by UV spectrophotomertric method. The percentage of active ingredients in both the formulations was found to be $101.22 \%$ in formulation 1 and 102.15 in formulation 2. This is in accordance with B.P.

Disintegration time for both the formulations was noted and has been presented in the Table 1. Disintegration test was performed on both the formulations. Mean disintegration time for formulation 1 was found to be 8 minutes and mean disintegration time for formulation 2 was 11 minutes. The difference in the mean disintegration time of two formulations may be due to difference in the binders. Hardness test was performed on both the formulations. The hardness of the formulation 1 was $7 \mathrm{Kg} / \mathrm{cm}^{2}$ and the hardness of formulation 2 was $5 \mathrm{Kg} / \mathrm{cm}^{2}$. Hardness of formulation 1 was found to be more than the formulation 2 as gelatin has more binding properties than starch.

Dissolution behaviour of both formulations have been shown in the Table 2 and presented in Figure 1.

Table 1: Assay, disintegration time and hardness test values of formulation 1 and 2 .

\begin{tabular}{|l|c|c|}
\hline \multicolumn{1}{|c|}{ In vitro parameter } & Formulation 1 & Formulation 2 \\
\hline Assay of Active Drug (\%) & 101.22 & 102.15 \\
\hline Disintegration Time (Minutes) & 8 & 11 \\
\hline Hardness $\left(\mathrm{kg} / \mathrm{cm}^{2}\right)$ & 7 & 5 \\
\hline
\end{tabular}


Table 2: Dissolution rate study of formulations 1 and 2.

\begin{tabular}{||c|c|c||}
\hline Time (minutes) & \multicolumn{2}{|c|}{ Percent dissolved } \\
\hline & Formulation 1 & Formulation 2 \\
\hline 15 & 32.39 & 28.36 \\
\hline 30 & 53.46 & 45.03 \\
\hline 45 & 68.27 & 62.03 \\
\hline 60 & 90.68 & 85.49 \\
\hline 90 & 96.89 & 90.68 \\
\hline 120 & 100.09 & 100.01 \\
\hline
\end{tabular}

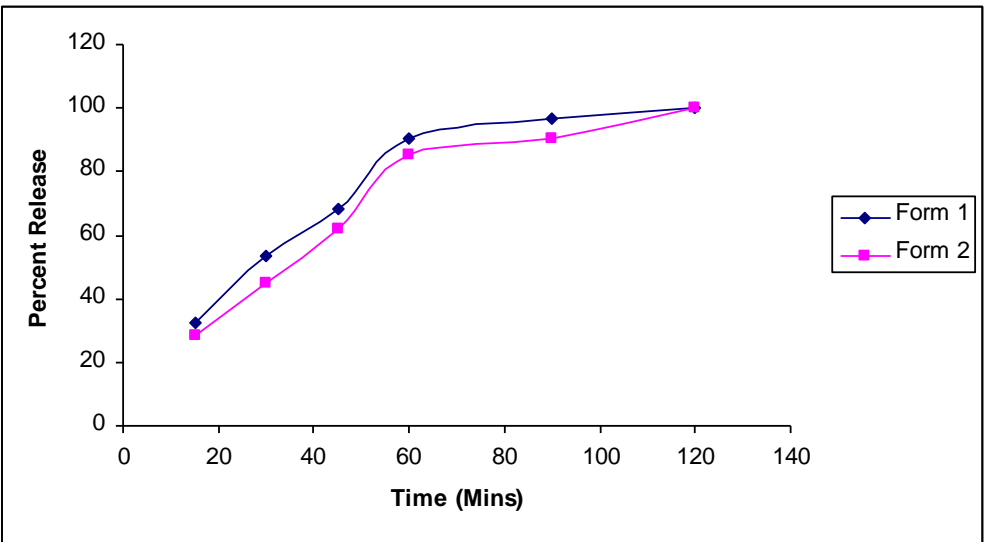

Fig. 1: Dissolution vs time profile of formulations 1 and 2.

Dissolution test was performed on both formulations. In the second formulation ofloxacin was released in a slower pattern in comparison with the first formulation. After first 15 minutes formulation 1 was released up to $32.39 \%$ while formulation 2 was released up to $28.36 \%$. After 30 minutes formulation 1 was released up to $53.46 \%$ and the formulation 2 was released up to $45.03 \%$. After 45 minutes formulation 1 was released up to $68.27 \%$ and formulation 2 was released up to $62.03 \%$. After 60 minutes formulation 1 was released up to $90.68 \%$ and formulation 2 was released with a faster rate, which was up to $85.49 \%$. Dissolution tests were continued until complete drug was released from the tablets. After 90 minutes the active ingredient in formulation 1 was released up to $96.89 \%$ and the active ingredient in formulation 2 was released about 
90.68\%. After 120 minutes formulation 1 was released up to $100.09 \%$ and the formulation 2 was released up to $100.01 \%$.

On the basis of this comparison it can be concluded that formulation 1 released the ofloxacin in a slightly rapid pattern. In formulation 1 drug was released more quickly which might be due to presence of gelatin. Inspite of the fact that gelatin has more binding power as compared to starch, it liberated drug more quickly than starch. Perhaps gelatin helped in liberation of drug into water.

\section{In-vivo evaluation}

The mean ofloxacin plasma concentration versus time profile for the formulation 1 has been represented in Figures 2 and 3 and the mean ofloxacin plasma concentration versus time profile for formulation 2 has been represented in Figures 4 and 5. Average plasma concentrations versus time for both formulations have been represented in Figure 6 . Both the formulations show fluctuations at certain points. On the average formulation 2 is more bioavailable than formulation 1 .

Pharmacokinetic parameters for formulations 1 and 2 of all the eight healthy subjects have been shown in Tables 3 and 4 respectively.

Pharmacokinetic parameters along with statistical analysis for formulation 1 and 2 have been presented in the Table 5.
Several pharmacokinetic parameters observed in our study were comparable to values previously reported $^{3-6}$ in studies of adult subjects. The peak plasma drug concentration, $\mathrm{C}_{\max }$, represents the maximum plasma drug concentration obtained after oral administration of drug. For many drugs, a relationship is found between the pharmacodynamic drug effects and the plasma concentration. $\mathrm{C}_{\max }$ provides indications that the drug is sufficiently systemically absorbed to provide therapeutic response. In addition $\mathrm{C}_{\max }$ provides warning of possibly toxic levels of drug. ${ }^{12}$ In a pervious study conducted on human beings maximum plasma concentration $\left(\mathrm{C}_{\max }\right)$ was found to be $1.6-2.2 \mathrm{mg} / \mathrm{L}$ with the dose of $200 \mathrm{mg}$, $3.2-4.3 \mathrm{mg} / \mathrm{L}$ after the dose of $400 \mathrm{mg}$ and 6.7-8.1 $\mathrm{mg} / \mathrm{L}$ with the dose of $600 \mathrm{mg}$ of ofloxacin. ${ }^{13}$

In this study maximum plasma concentrations $\left(\mathrm{C}_{\max }\right)$ for formulation 1 were found to be ranging from $0.98-1.84 \mu \mathrm{g} / \mathrm{ml}$ with mean $1.44125 \pm$ $1.8367 \mu \mathrm{g} / \mathrm{ml}$ and for the formulation 2 maximum plasma concentrations $\left(\mathrm{C}_{\max }\right)$ were ranging from 0.86-1.9 $\mu \mathrm{g} / \mathrm{ml}$ with the mean value $1.5 \pm$ $1.5898 \mu \mathrm{g} / \mathrm{ml}$. These values were found to be almost closer to the values which have already been reported in the literature. The slight difference might be due to differences in body composition of different persons. The mean maximum plasma concentration values are consistent 
Table 3: Pharmacokinetic parameters of all subjects after administering formulation 1.

\begin{tabular}{|c|c|c|c|c|c|c|c|c|c|c||}
\hline $\begin{array}{c}\text { Subject } \\
\text { No. }\end{array}$ & $\begin{array}{c}\text { AUMC }(0-\infty) \\
\left(\mu \mathrm{g} . \mathrm{h}^{2} / \mathrm{ml}\right)\end{array}$ & $\begin{array}{c}\mathrm{AUC}(0-\infty) \\
(\mu \mathrm{g} . \mathrm{h} / \mathrm{ml})\end{array}$ & $\begin{array}{c}\mathrm{C}_{\max } \\
(\mu \mathrm{g} / \mathrm{ml})\end{array}$ & $\begin{array}{c}\mathrm{T}_{\max } \\
(\mathrm{h})\end{array}$ & $\begin{array}{c}\mathrm{MRT} \\
(\mathrm{h})\end{array}$ & $\begin{array}{c}\mathrm{Ke} \\
\left(\mathrm{Hr}^{-1}\right)\end{array}$ & $\begin{array}{c}\mathrm{T}_{1 / 2}(\mathrm{el}) \\
(\mathrm{h})\end{array}$ & $\begin{array}{c}\mathrm{Vd} \\
(\mathrm{L} / \mathrm{Kg})\end{array}$ & $\begin{array}{c}(\mathrm{VSS}) \\
(\mathrm{L} / \mathrm{Kg})\end{array}$ & $\begin{array}{c}\mathrm{CL}(\mathrm{ml} / \\
\mathrm{min})\end{array}$ \\
\hline 1 & 34.410 & 7.577 & 1.23 & 1.0 & 4.5411 & 0.2202 & 3.1470 & 119.86 & 5.812 & 26.394 \\
\hline 2 & 63.576 & 10.980 & 1.84 & 1.0 & 5.7899 & 0.1727 & 4.0124 & 105.46 & 3.146 & 18.214 \\
\hline 3 & 37.892 & 8.555 & 1.64 & 1.0 & 4.4293 & 0.2258 & 3.0695 & 103.55 & 5.278 & 23.378 \\
\hline 4 & 40.180 & 8.281 & 1.16 & 1.0 & 4.8527 & 0.2061 & 3.3629 & 117.21 & 4.978 & 24.155 \\
\hline 5 & 29.425 & 6.555 & 0.98 & 1.0 & 4.4889 & 0.2228 & 3.1108 & 136.96 & 6.797 & 30.511 \\
\hline 6 & 59.104 & 10.395 & 1.68 & 1.0 & 5.6858 & 0.1759 & 3.9403 & 109.40 & 3.384 & 19.240 \\
\hline 7 & 38.450 & 8.1925 & 1.41 & 1.0 & 4.6933 & 0.2131 & 3.2525 & 114.58 & 5.202 & 24.413 \\
\hline 8 & 41.097 & 8.907 & 1.59 & 1.0 & 4.6138 & 0.2167 & 3.1974 & 103.59 & 4.866 & 22.453 \\
\hline SUM & 344.136 & 69.443 & 11.53 & 8.0 & 39.0948 & 1.6532 & 27.0927 & 910.60 & 39.463 & 188.757 \\
\hline MEAN & 43.0170 & 8.6804 & 1.44125 & 1.000 & 4.8869 & 0.2067 & 3.3866 & 113.826 & 4.933 & 23.595 \\
\hline \pm SEM & 0.2893 & 0.8346 & 1.8367 & 0.000 & 1.3587 & 6.9207 & 1.6321 & 0.2983 & 0.9138 & 0.5070 \\
\hline \hline
\end{tabular}


Table 4: Pharmacokinetic parameters of all subjects after administering formulation 2.

\begin{tabular}{|c|c|c|c|c|c|c|c|c|c|c||}
\hline $\begin{array}{c}\text { Subject } \\
\text { No. }\end{array}$ & $\begin{array}{c}\text { AUMC }(0-\infty) \\
\left(\mu \mathrm{g} . \mathrm{h}^{2} / \mathrm{ml}\right)\end{array}$ & $\begin{array}{c}\text { AUC }(0-\infty) \\
(\mu \mathrm{g} . \mathrm{h} / \mathrm{ml})\end{array}$ & $\begin{array}{c}\mathrm{Cmax} \\
(\mu \mathrm{g} / \mathrm{ml})\end{array}$ & $\begin{array}{c}\text { Tmax } \\
(\mathrm{h})\end{array}$ & $\begin{array}{c}\text { MRT } \\
(\mathrm{h})\end{array}$ & $\begin{array}{c}\mathrm{Ke} \\
\left(\mathrm{Hr}^{-1}\right)\end{array}$ & $\begin{array}{c}\mathrm{T}_{1 / 2}(\mathrm{el}) \\
(\mathrm{h})\end{array}$ & $\begin{array}{c}\mathrm{Vd} \\
(\mathrm{L} / \mathrm{Kg})\end{array}$ & $\begin{array}{c}(\mathrm{VSS}) \\
(\mathrm{L} / \mathrm{Kg})\end{array}$ & $\begin{array}{c}\mathrm{CL}(\mathrm{ml} \\
/ \mathrm{min})\end{array}$ \\
\hline 1 & 40.1747 & 10.036 & 1.17 & 0.5 & 4.0031 & 0.2498 & 2.7741 & 79.77 & 4.978 & 19.928 \\
\hline 2 & 28.2362 & 8.2578 & 1.78 & 0.5 & 3.4193 & 0.2925 & 2.3696 & 82.81 & 7.083 & 24.220 \\
\hline 3 & 33.4325 & 9.2312 & 1.95 & 0.5 & 3.6217 & 0.2761 & 2.5098 & 78.47 & 5.982 & 21.666 \\
\hline 4 & 24.446 & 6.8337 & 0.86 & 0.5 & 3.5773 & 0.2795 & 2.4791 & 104.70 & 8.181 & 29.267 \\
\hline 5 & 28.4112 & 7.8462 & 1.19 & 0.5 & 3.6210 & 0.2762 & 2.5094 & 92.30 & 7.039 & 25.490 \\
\hline 6 & 52.8183 & 10.771 & 1.91 & 0.5 & 4.9038 & 0.2039 & 3.3983 & 91.06 & 3.787 & 18.569 \\
\hline 7 & 37.8012 & 9.6637 & 1.62 & 0.5 & 3.9117 & 0.2556 & 2.7108 & 80.96 & 5.291 & 20.696 \\
\hline 8 & 38.2687 & 9.6137 & 1.64 & 0.5 & 3.9806 & 0.2512 & 2.7586 & 82.81 & 5.226 & 20.804 \\
\hline SUM & 283.589 & 72.2532 & 12.12 & 4.0 & 31.0385 & 2.0849 & 21.5097 & 692.87 & 47.568 & 180.638 \\
\hline MEAN & 35.4486 & 9.0317 & 1.515 & 0.500 & 3.8798 & 0.2606 & 2.6887 & 86.609 & 5.946 & 22.580 \\
\hline \pm SEM & 0.3337 & 0.8805 & 1.5898 & 0.000 & 1.4668 & 6.0291 & 1.7620 & 0.3354 & 0.8404 & 0.5333 \\
\hline \hline
\end{tabular}


Table 5: Statistical analysis of pharmacokinetic parameters for formulation 1 and 2.

\begin{tabular}{|l|c|c|}
\hline \multicolumn{1}{|c|}{ Parameters } & Formulation 1 & Formulation 2 \\
\hline $\mathrm{C}_{\max }(\mu \mathrm{g} / \mathrm{ml})$ & $1.4412 \pm 1.8367$ & $1.515 \pm 1.5898^{\mathrm{ns}}$ \\
\hline $\mathrm{T}_{\max }(\mathrm{Hrs})$ & $1.00 \pm 0.00$ & $0.5 \pm 0.00$ \\
\hline AUC $(\mu \mathrm{g} \cdot \mathrm{h} / \mathrm{ml})$ & $8.6804 \pm 0.8346$ & $9.0317 \pm 0.8805^{\mathrm{ns}}$ \\
\hline AUMC $\left(\mu \mathrm{g} . \mathrm{h}^{2} / \mathrm{ml}\right)$ & $43.017 \pm 0.2893$ & $35.4486 \pm 0.3337^{\mathrm{ns}}$ \\
\hline $\mathrm{MRT}(\mathrm{Hrs})$ & $4.8869 \pm 1.3587$ & $3.8798 \pm 1.4668^{* *}$ \\
\hline $\mathrm{Ke}\left(\mathrm{hr}^{-1}\right)$ & $0.2067 \pm 6.9207$ & $0.2606 \pm 6.0291^{* *}$ \\
\hline $\mathrm{t}_{1 / 2}(\mathrm{Hrs})$ & $3.3886 \pm 1.6321$ & $2.68 \pm 1.76^{* *}$ \\
\hline $\mathrm{VD}(\mathrm{L} / \mathrm{Kg})$ & $113.826 \pm 0.2983$ & $86.609 \pm 0.3354^{* *}$ \\
\hline $\mathrm{Vss}(\mathrm{L} / \mathrm{Kg})$ & $4.833 \pm 0.9138$ & $5.94 \pm 0.84^{\mathrm{ns}}$ \\
\hline $\mathrm{Cl}(\mathrm{ml} / \mathrm{min})$ & $23.595 \pm 0.5070$ & $22.580 \pm 0.5333^{\mathrm{ns}}$ \\
\hline
\end{tabular}

$\mathrm{ns}=$ non-significant difference $(\mathrm{p}>0.05)$

$*$ = significant difference $(\mathrm{p}<0.05)$

$* *$ = highly significant difference $(\mathrm{p}<0.01)$

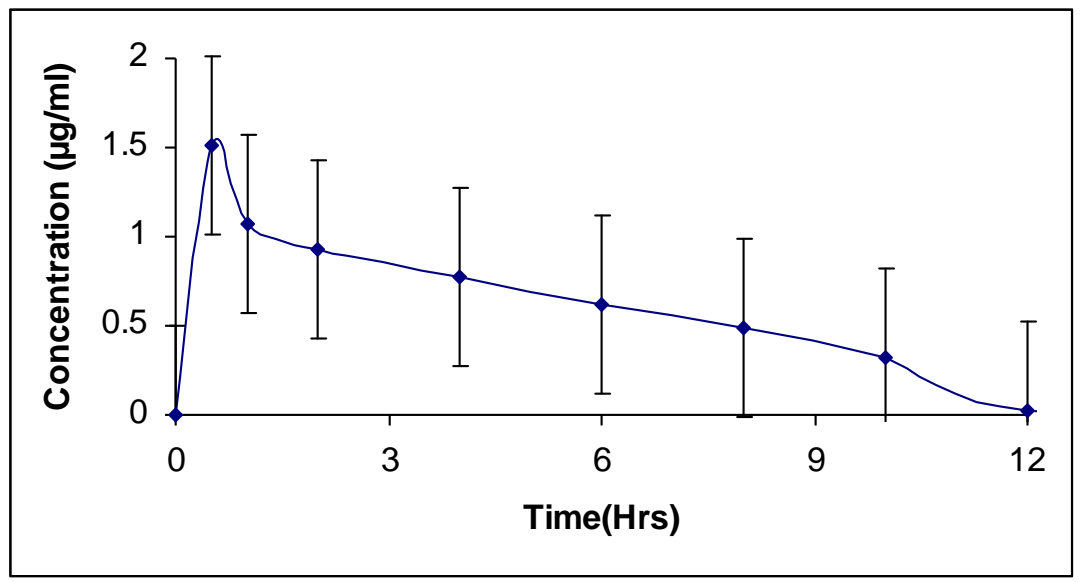

Fig. 2: Mean \pm SEM plasma concentration vs time profile after administering formulation 1 in eight subjects 


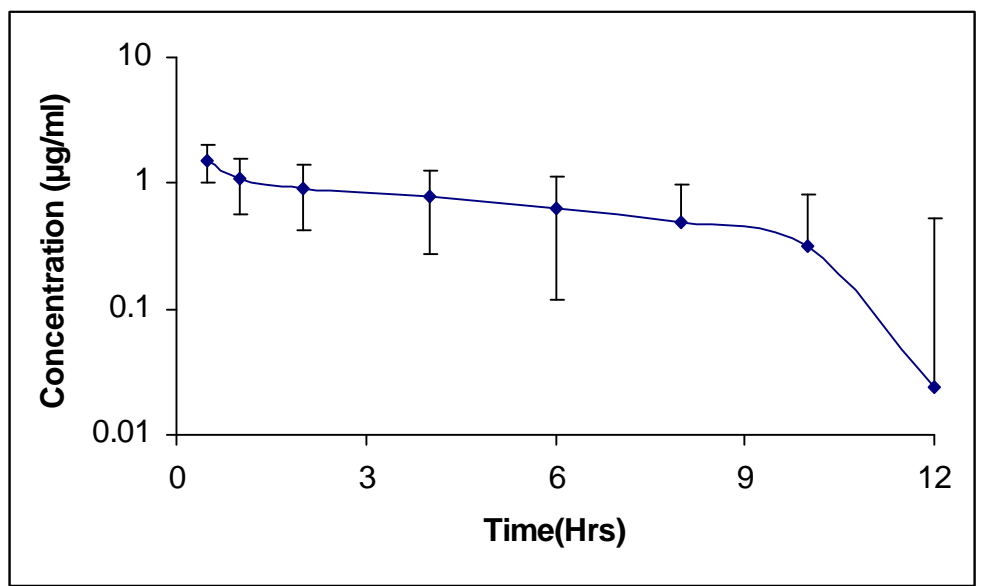

Fig. 3: Mean \pm semi-log plot of plasma concentrations vs time of ofloxacin after administering of formulation 1 .

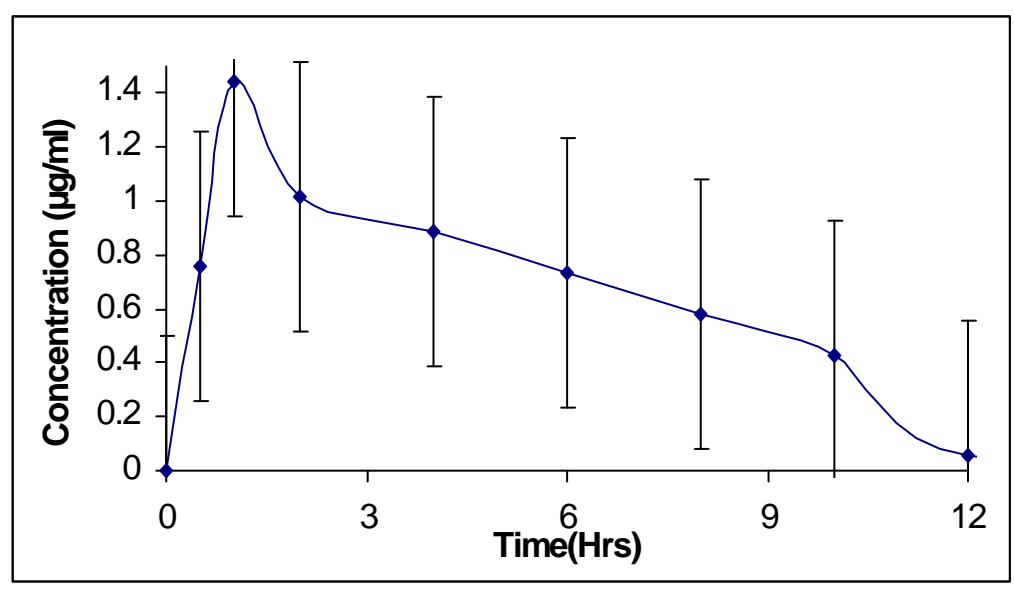

Fig. 4: Mean \pm SEM plasma concentrations vs time profile after administering formulation 2 in eight subjects. 


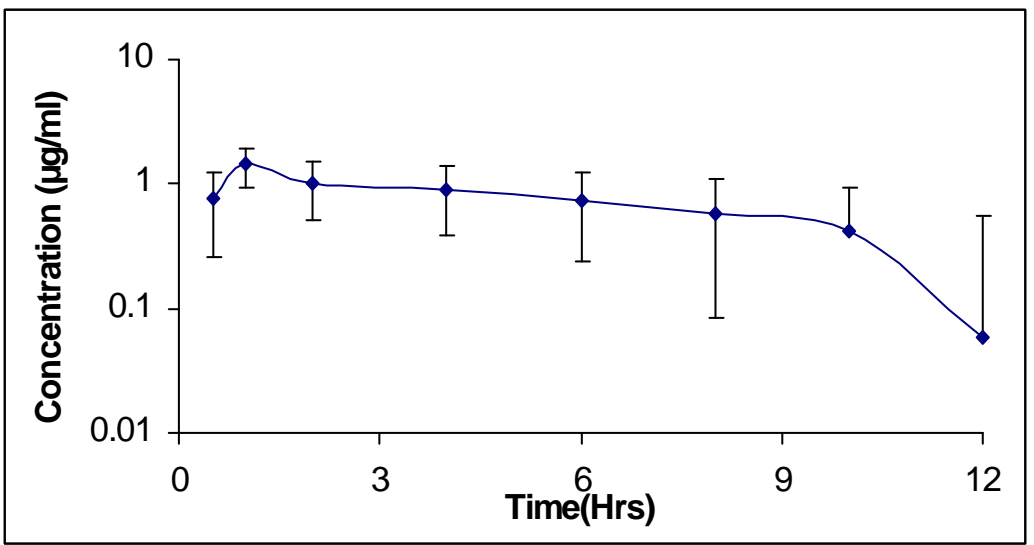

Fig. 5: Mean \pm semi-log plot of plasma concentrations vs time of ofloxacin after administering of formulation 2 .

in both these formulations. Paired ttest was performed on the average $\mathrm{C}_{\max }$ values for two formulations. There was no significant difference between the two formulations at $95 \%$ confidence interval.

The time of peak plasma concentration, $\mathrm{T}_{\max }$, corresponds to the time required to reach maximum drug concentration after drug administration. At $\mathrm{T}_{\max }$, peak drug absorption occurs and the rate of drug absorption exactly equals to the rate of drug elimination. ${ }^{12}$

In a pervious study conducted on human volunteers ofloxacin has $\mathrm{T}_{\max }$ 0.5 to $3 \mathrm{~h}^{14}$ In another study conducted on healthy young volunteers, $\mathrm{T}_{\max }$ were repoted to be $1.6 \pm 1.2$ hours after the dose of 100 $\mathrm{mg}, 1.2 \pm 0.4$ hours with the dose of $300 \mathrm{mg}$ and $1.2 \pm 0.6$ with the dose of $600 \mathrm{mg}$ of ofloxacin. ${ }^{15}$ In this study $\mathrm{T}_{\max }$ of the formulation 1 was 1.0 hour in all volunteers and $\mathrm{T}_{\max }$ of formulation 2 was 0.5 hours in all subjects. These two values were found in the range of values in pervious study.

In a pervious study conducted on human volunteers apparent volume of distribution of the drug was reported to be $1.0-1.5 \mathrm{~L} / \mathrm{kg}$ with the dose of $200 \mathrm{mg}$ of ofloxacin. ${ }^{13}$ In this study the volume of distribution (VD) for formulation 1 was ranging from $103.55-136.96-\mathrm{L} / \mathrm{Kg}$ with mean $113.826 \pm 0.2983 \mathrm{~L} / \mathrm{Kg}$ and for the formulation 2 was ranging from $79.77-104.70 \mathrm{~L} / \mathrm{Kg}$ with mean 86.609 $\pm 0.3354 \mathrm{~L} / \mathrm{Kg}$. These values are very greater than reported in the pervious studies of healthy human volunteers. This difference may be due to alteration of body composition of different individuals and also due to different binding properties used in this study that's gelatin and starch.

Volume of steady state (Vss) of the formulation 1 was ranging from 
3.146-6.797 L/Kg with mean $4.933 \pm$ $0.9138 \mathrm{~L} / \mathrm{Kg}$ and of formulation 2 was ranging from $4.978-8.181 \mathrm{~L} / \mathrm{Kg}$ with mean $5.946 \pm 0.8404 \mathrm{~L} / \mathrm{Kg}$. Elimination rate constant i.e. Ke of the formulation 1 was ranging from 0.1727-0.2258 with mean $0.2067 \pm$ 6.9207 and for the formulation 2 was ranging from $0.2039-0.2925$ with mean $0.2602 \pm 6.0291$. These values are constant in both formulations.

\section{Conclusion}

There is no big difference in the pharmacokinetic parameters of two formulations. As formulation 2 has greater AUC than formulation 1, on the basis of this it can be concluded that formulation 2 is slightly more better than formulation 1 .

\section{REFERENCES}

1- J. Mary. Myak et al., "Liponcott's Illustrated Review of Pharmacology", $2^{\text {nd }}$ ed., Lipponcott-Raven USA, 2000, p. 327

2- V. T. Andrioe, "Quinolones", In Mandell et al. (Eds), Principles and Practice of Infectious Diseases, Churchill Livingstone, New York, 1991, pp. 334-345.

3- P. Y. Chou, Y. K. Leung and W. W. S. Ng, Infection, 14 (Suppl. 4), S237 (1986).

4- R. N. Gruneverg, D. Felmingham, M. D. O'Hare, M. J. Robbins, Perry $\mathrm{K}$, et al., Journal of Antimicribial Chemotherapy; 22 (Suppl. C), 9 (1988).
5- E. Rubinstein, Z. Marck, G Keren Alkan M, S. Berger, et al., Infection, 14 (Suppl. 1), S20 (1986).

6- K. Sato. Y. Inoue, T. Fujii, J. Aoyama and S. Misuhashi, ibid., 14 (Suppl.4): S226 (1986).

7- S. M. Smith, Antimicrobial Agents and Chemotherapy, 29, 325 (1986).

8- A. Toress, R. Fernandez-Roblas, B. Mendez and F. Soriano, Infection, 14 (Suppl. 4), S233 (1986).

9- M. A. Smythe and M. J. Rybak, The Annals of Pharmacotherapy, 23, 839 (1990).

10- P. C. Fuchs, American Journal of Medicine, 87 (Suppl. 8C), 10S (1989).

11- H. Jalalizadeh., M. Amini., V. Ziaee., A. Safa., H. Farsam. and Shafiee A., J. Pharma. Biomed. Analysis, 35, 665 (2004).

12- Leon Shargel, "Applied Biopharmaceutics \& Pharmacokinetics", $4^{\text {th }}$ Ed., 1999, pp. 256-259.

13- C. Kenneth Lamp, M. Elaine Bailey and J. Michael Rybak, Clin. Pharmacokinet., 22, 32 (1992).

14- R. Wise and M. R. Lockley, J. Antimicrob. Chemother., 22 (Suppl. C), 59 (1988).

15- R. Allan Tunkel and W. Michael Scheld, Infect. Control Hosp. Epidemiol., 12, 549 (1991). 